\title{
Scientific Evidence of Interventions Using the Mediterranean Diet: A Systematic Review
}

\author{
Lluís Serra-Majem, PhD, MD, Blanca Roman, MD, and Ramón Estruch, PhD, MD
}

The Mediterranean Diet has been associated with greater longevity and quality of life in epidemiological studies, the majority being observational. The application of evidence-based medicine to the area of public health nutrition involves the necessity of developing clinical trials and systematic reviews to develop sound recommendations. The purpose of this study was to analyze and review the experimental studies on Mediterranean diet and disease prevention. A systematic review was made and a total of 43 articles corresponding to 35 different experimental studies were selected. Results were analyzed for the effects of the Mediterranean diet on lipoproteins, endothelial resistance, diabetes and antioxidative capacity, cardiovascular diseases, arthritis, cancer, body composition, and psychological function. The Mediterranean diet showed favorable effects on lipoprotein levels, endothelium vasodilatation, insulin resistance, metabolic syndrome, antioxidant capacity, myocardial and cardiovascular mortality, and cancer incidence in obese patients and in those with previous myocardial infarction. Results disclose the mechanisms of the Mediterranean diet in disease prevention, particularly in cardiovascular disease secondary prevention, but also emphasize the need to undertake experimental research and systematic reviews in the areas of primary prevention of cardiovascular disease, hypertension, diabetes, obesity, infectious diseases, age-re-

Dr. Serra-Majem is with the Department of Clinical Sciences. University of Las Palmas de Gran Canaria, Spain, and the Foundation for the Advancement of the Mediterranean diet, University of Barcelona Science Park, Spain; Dr. Roman is with the Foundation for the Advancement of the Mediterranean Diet; Dr. Estruch is with the Department of Internal Medicine, Hospital Clinic, Instituto de Investigaciones Biomédicas August Pi Sunyer (IDIBAPS), University of Barcelona, Spain

Please address all correspondence to: Professor Lluís Serra-Majem, President, Foundation for the Advancement of the Mediterranean Diet, Parc Cientific de Barcelona, Universitat de Barcelona, Baldiri Reixac, 4 Torre D 08028 Barcelona, Spain; Phone: 34-934-034-541; Fax: 34-934-034-543; E-mail: dietmed@pcb.ub.es lated cognitive impairment, and cancer, among others. Interventions should use food scores or patterns to ascertain adherence to the Mediterranean diet. Further experimental research is needed to corroborate the benefits of the Mediterranean diet and the underlying mechanisms, and in this sense the methodology of the ongoing PREDIMED study is explained.

Key words: Mediterranean diet, prevention, evidencebased nutrition, dietary interventions, clinical trails

(C) 2006 International Life Sciences Institute

doi: 10.1301/nr.2006.feb.S27-S47

\section{INTRODUCTION}

Epidemiological studies ${ }^{1-3}$ have observed great geographical differences in the incidence rates of cardiovascular disease. Compared with northern European countries or the United States, there is a low incidence of coronary heart disease (CHD) in countries of southern Europe, such as France, Spain, Greece, and Italy. The Mediterranean food pattern has been the factor most frequently invoked to explain this difference. The term "Mediterranean diet" reflects the dietary patterns characteristics of several countries in the Mediterranean Basin during the early 1960s. The association between greater longevity and reduced mortality and morbidity for CHD has also been observed for certain cancers and other nutrition-related diseases. The common dietary food patterns in these countries have substantiated this concept, ${ }^{4,5}$ although the data come mostly from observational studies.

Such patterns were defined in 1993 at the International Conference on the Diets of the Mediterranean, having also been previously defined in other meetings. ${ }^{4-7}$ They are comprised of:

- Abundant plant foods (fruits, vegetables, breads, other forms of cereals, beans, nuts, and seeds);

- Minimally processed, seasonally fresh, and locally grown foods;

- Fresh fruits as the typical daily dessert with sweets 
based on nuts, olive oil, and concentrated sugars or honey consumed during feast days;

- Olive oil as the principal source of dietary lipids;

- Dairy products (mainly cheese and yogurt) consumed in low to moderate amounts;

- Fewer than four eggs consumed per week;

- Red meat consumed in low frequency and amounts; and

- Wine consumed in low to moderate amounts, generally with meals.

This characteristic definition of the Mediterranean diet and its typical composition is not without ambiguities, which require certain consideration. ${ }^{8-10}$

Evidence-based nutrition is the application of the principles of evidence-based medicine to the area of food and nutrition, in both clinical practice and in the public health.

Usually, in the field of public health nutrition/dietary guidelines/policy development, the application of evidence-based nutrition has several weaknesses, since there are some limitations when analyzing the effect that diet modification has on health:

- The modification of a diet not only requires much collaboration from the patient but also of the environment, with convenient access to products and willingness to buy and cook the food according to the dietary plan. Moreover, measuring dietary adherence entails greater effort from both the participant and the investigator.

- The complexity of dietary modifications makes it difficult to develop a double-blind intervention to analyze its effects on health.

- The enormous diversity of food habits, basal metabolic status, and nutritional objectives and dietary guidelines worldwide are limitations for making comparisons between studies developed in different contexts.

There is very small number of systematic reviews analyzing the effect of the Mediterranean diet on healthrelated issues, and also the number of randomized, controlled clinical trials is scarce (less than 50). In contrast, the worldwide popularity of the Mediterranean diet as a healthy and recommended diet is evident in the proliferation of media attention (more than 740,000 citations in Google ${ }^{\circledR}$ as of January 2005).

Most of the scientific articles published are observational epidemiological studies (primarily ecological or case control studies and a few cohorts). Almost all the reviews published are non-systematic and reflect an opinion or a collection of self-selected articles rather than an objective analysis of sound evidence.

The objective of this study is to analyze the literature published on the Mediterranean diet and to review all experimental studies analyzing the Mediterranean diet in disease prevention.

\section{METHODS}

We searched MEDLINE (National Library of Medicine, Bethesda, MD) for relevant articles about the Mediterranean diet and prevention of certain pathologies published from October 2004 to January 2005. We used the keywords "Mediterranean diet," "health," "cancer," "cardiovascular disease," "bone disease," "prevention," and combinations such as "Mediterranean diet and health," "Mediterranean diet and cancer prevention," "Mediterranean diet and cardiovascular disease," and "Mediterranean diet and bone health." We narrowed the search to clinical trials published in English and limited to those conducted in humans. We focused the search on articles referring to the Mediterranean diet as a whole and excluded studies regarding specific foods of this diet. We also excluded those articles evaluating the effects of an isolated intake of a Mediterranean menu instead of the prolonged effect of such a diet. Additional publications were identified from references provided in original papers.

We found 46 articles that met the inclusion criteria. Regarding the sample size, 22 of the studies had less than 50 subjects, 9 studies included 50 to 100 subjects, 9 studies had a sample of 101 to 500 subjects, 4 studies included a sample having between 500 and 1000 individuals, and 1 study included more than 1000 subjects.

\section{RESULTS}

A total of 489 articles studies were selected with the term "Mediterranean diet" and analyzed. The year distribution is shown in Figure 1. After excluding animal research, 416 studies remained, with only 324 having abstracts and, of these, 128 were reviews.

Among the original research articles, 55 were clinical trials and 41 of them were randomized clinical trails.

From the total of 55 clinical trial citations obtained, 43 were selected (12 excluded due to: language, intervention limited to one food and methodological weaknesses, among others), corresponding to 35 different studies. Studies were conducted in Italy, Spain, France, Great Britain, Chile, Sweden, Canada, Australia, United States, Denmark, Finland, and India, and the number of subjects ranged from 11 to 13,000 .

Studies were classified into six groups according to their objectives and outcome measures: lipoproteins/ endothelial resistance/ diabetes, cardiovascular disease, arthritis, cancer, body composition, and psychological function.

A first group consisted of different intermediate 


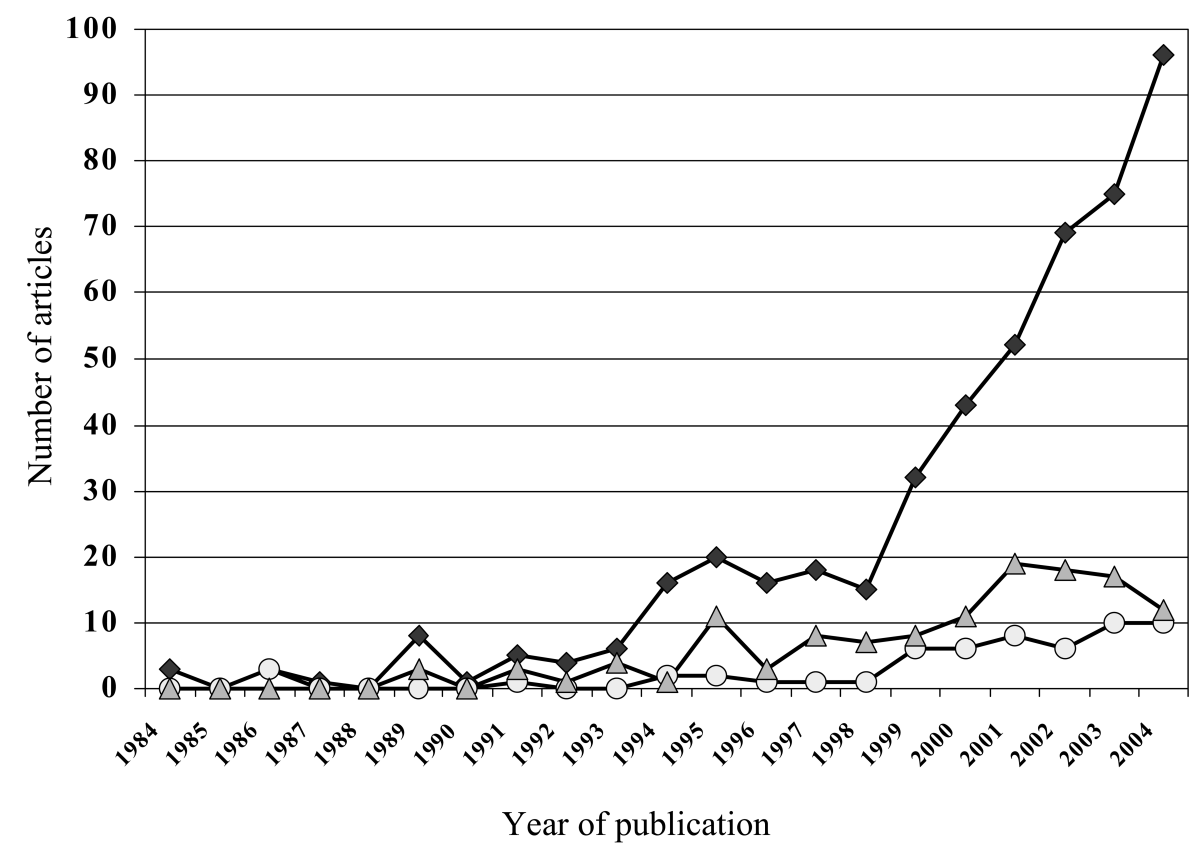

Figure 1. Number and type of articles published about the Mediterranean diet. $\bullet$, Publications; $\triangle$, reviews; $\bigcirc$, clinical trials.

outcomes such as lipoproteins, glycemic control, endothelial resistance, inflammation markers, and antioxidant capacity. It included 30 articles published from 1982 to 2004, with more than half (18) published from 2001, and only 5 before $1995 .^{11-40}$

A second group measured cardiovascular disease incidence or morbidity with five articles. ${ }^{41-45}$ A third group included two articles on arthritis. ${ }^{46,47}$ A fourth group focused on cancer with only one article. ${ }^{48}$ Three articles on body weight and obesity comprised the fifth group ${ }^{49-51}$ and the last group included two articles on psychological function. ${ }^{52,53}$

All results are summarized in Table 1. Most of the clinical trails in the first group analyzing the effect of Mediterranean diet on lipids found reductions in total cholesterol, low-density lipoprotein (LDL) cholesterol (decrease in small LDL particles number in some), tryglicerides, apoprotein B, and very-low-density lipoprotein (VLDL) cholesterol, and an increase in highdensity lipoprotein (HDL) cholesterol. An increase of the total plasma antioxidant capacity was also observed in two studies, but not in another. Endothelium function improved with the Mediterranean diet, and endothelialdependent vasodilatation was increased by adding nuts to the Mediterranean diet. Insulin resistance and metabolic syndrome were reduced after changing to a Mediterranean diet, but some studies showed no effects on insulin or glucose levels. All of the articles addressing cardiovascular disease and secondary prevention showed an odds ratio for fatal myocardial infarction between 0.25 and 0.7 . The single study on arthritis functionality and pain demonstrated benefits, and the sole study on cancer showed a risk reduction of $60 \%$ in the Mediterranean diet group. The studies on body weight also showed favorable results with the Mediterranean diet, particularly the study by McManus et al. ${ }^{51}$ which in addition to higher weight losses, showed greater compliances to diet therapies. Finally, the Mediterranean diet did not show any alterations in mood in the last group.

\section{DISCUSSION}

The aim of this article was not to cast doubts on the level of evidence for Mediterranean diet interventions but to emphasize the weaknesses of research on the Mediterranean diet and to stress the need for further research and systematic reviews. One of the most immediate conclusions obtained from this review is that the scientific evidence for the Mediterranean diet is mostly sustained by observational studies and personal reviews.

For some of the years during the period analyzed, the number of original articles related to the Mediterranean diet was similar to the number of reviews. Additionally, it is remarkable that most of the reviews are non-systematic and at times are very subjective and biased.

An example can be found in an interesting review article of the Mediterranean diet in Greece by Simopou$\operatorname{los}{ }^{54}$ The author cited 114 references, but none included Trichopoulou (author of 53 of the 284 references in the search "diet and Greece") or Kafatos (author of 28 of the 284 references). Another very similar article from the previously mentioned author ${ }^{55}$ reviewed the relationship between the Mediterranean diet and cancer in Greece, 


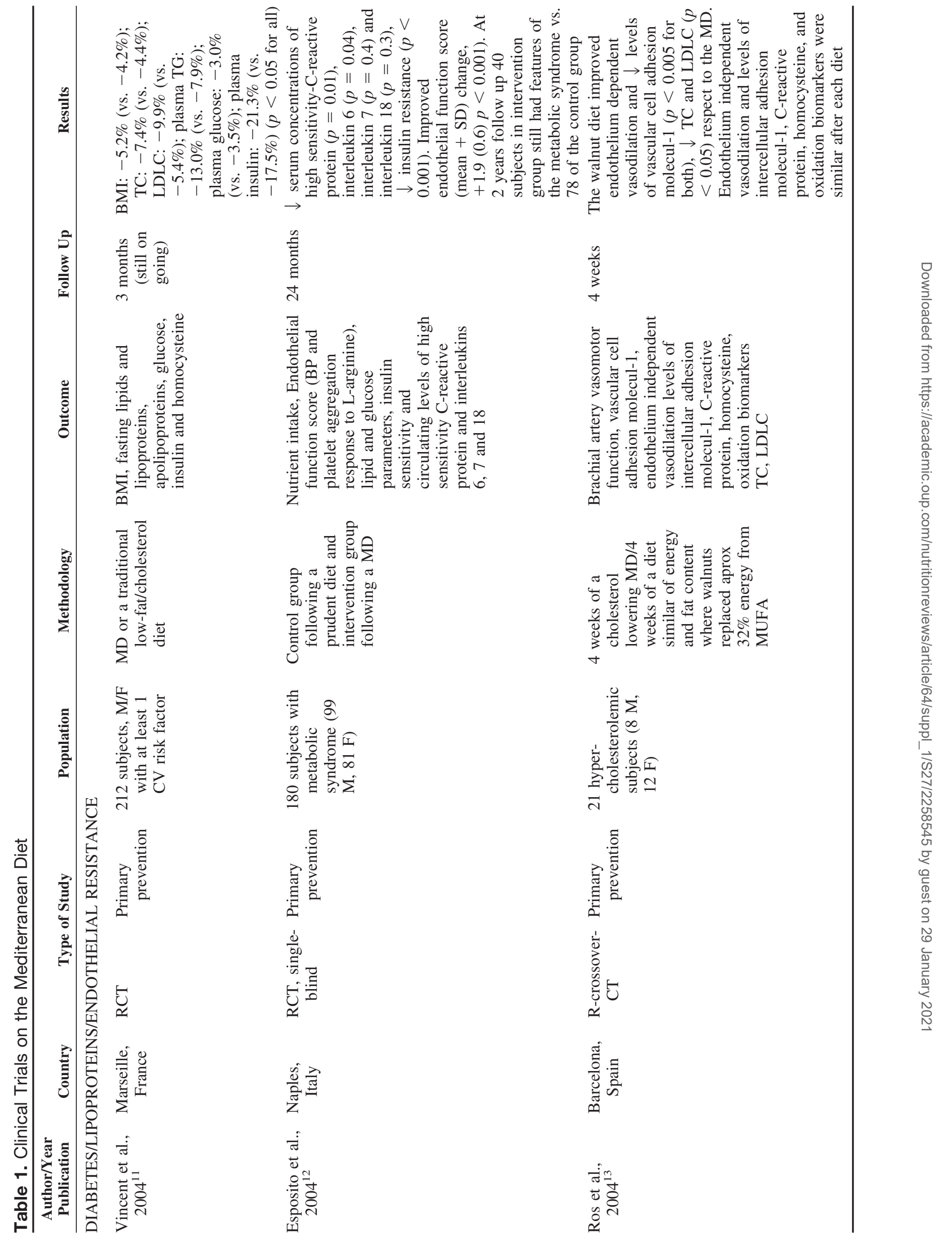




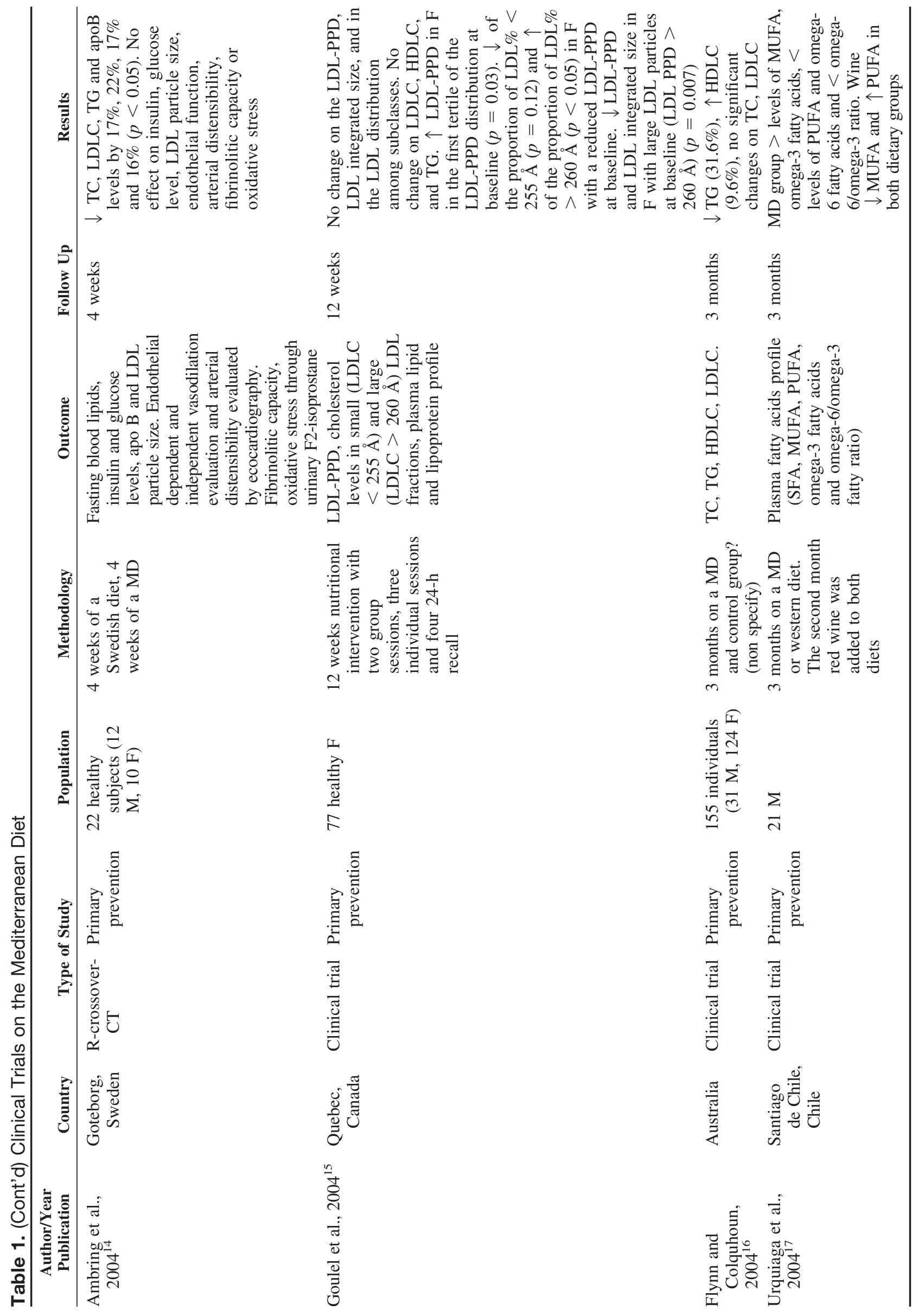




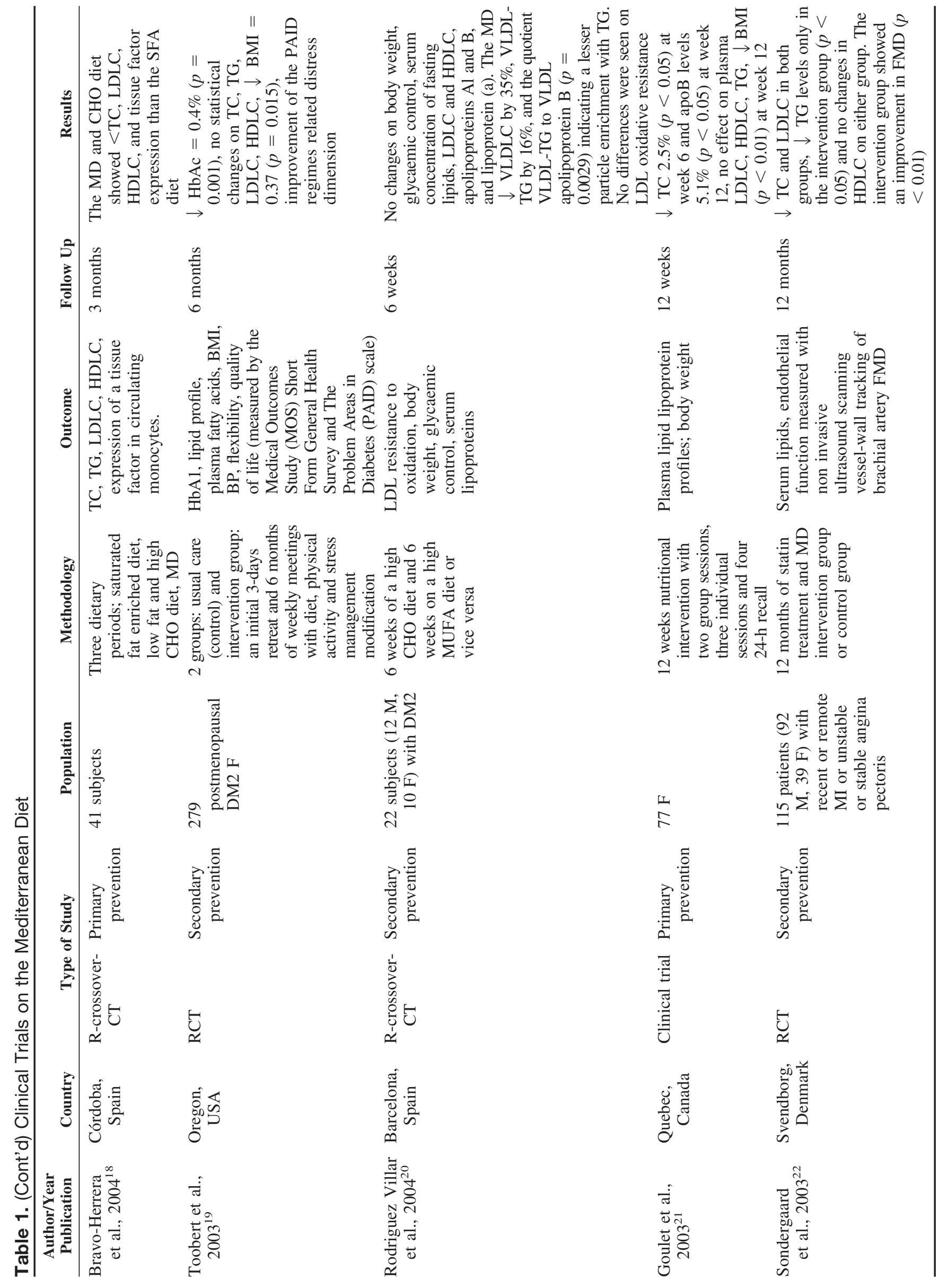




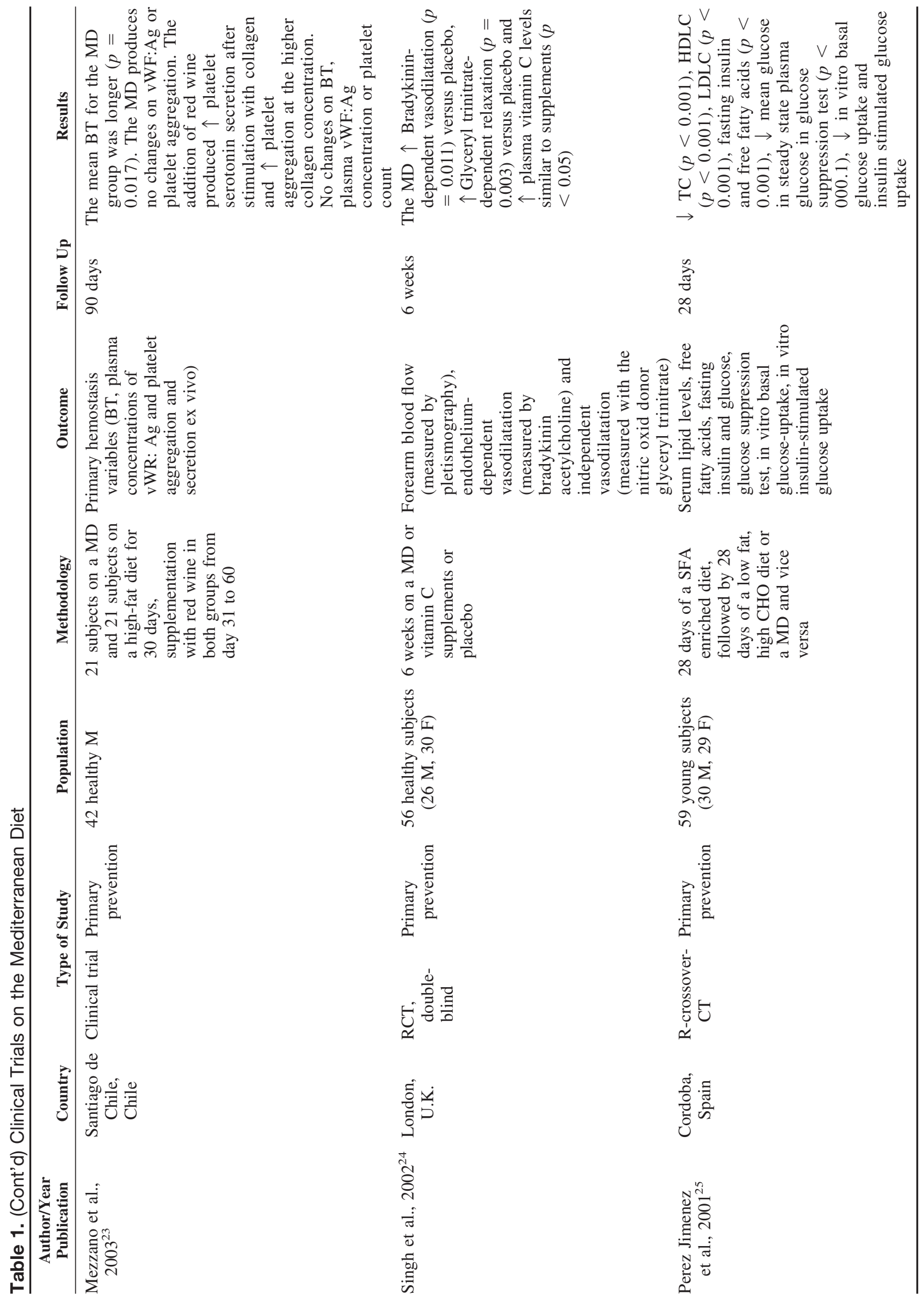




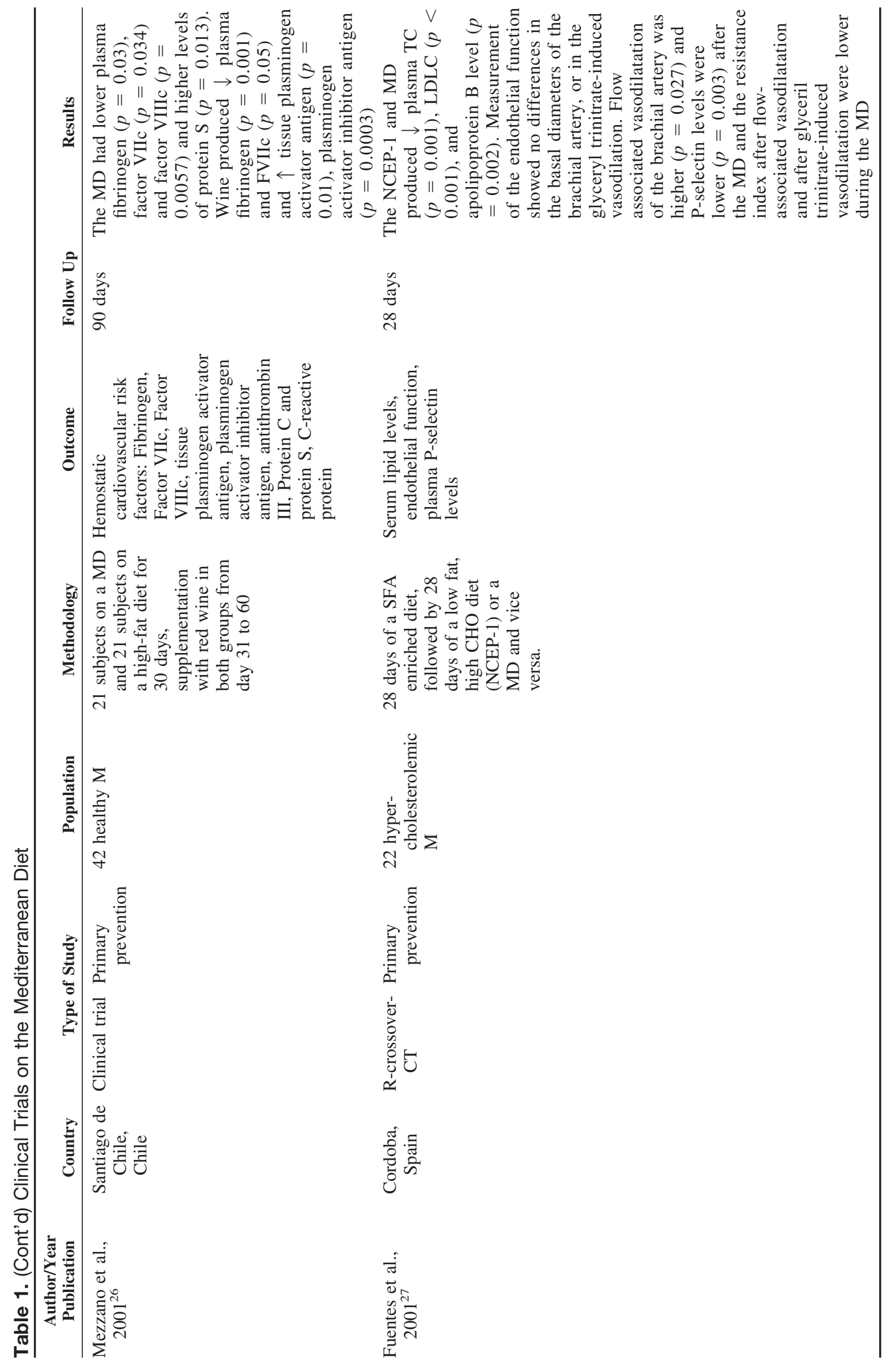




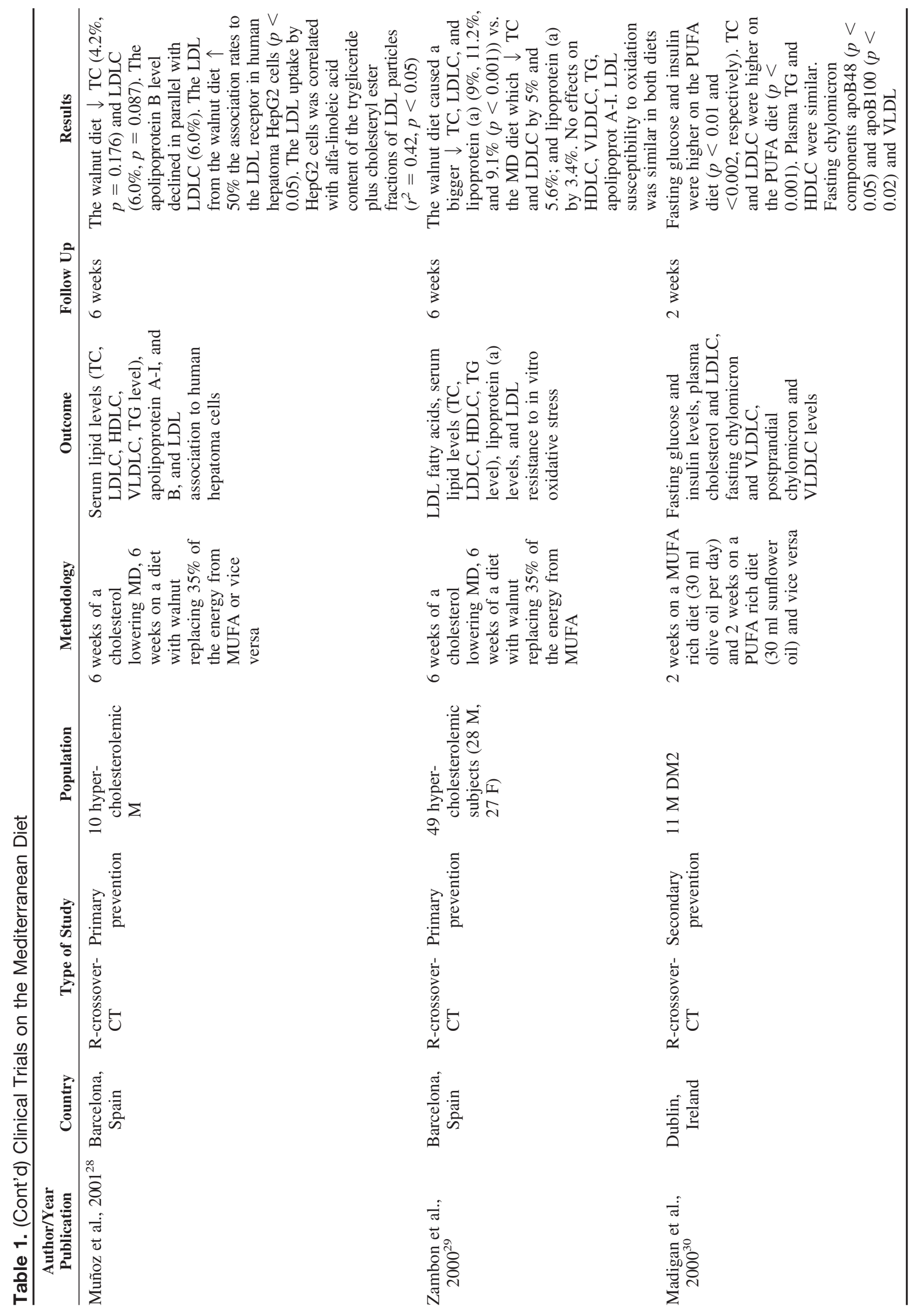




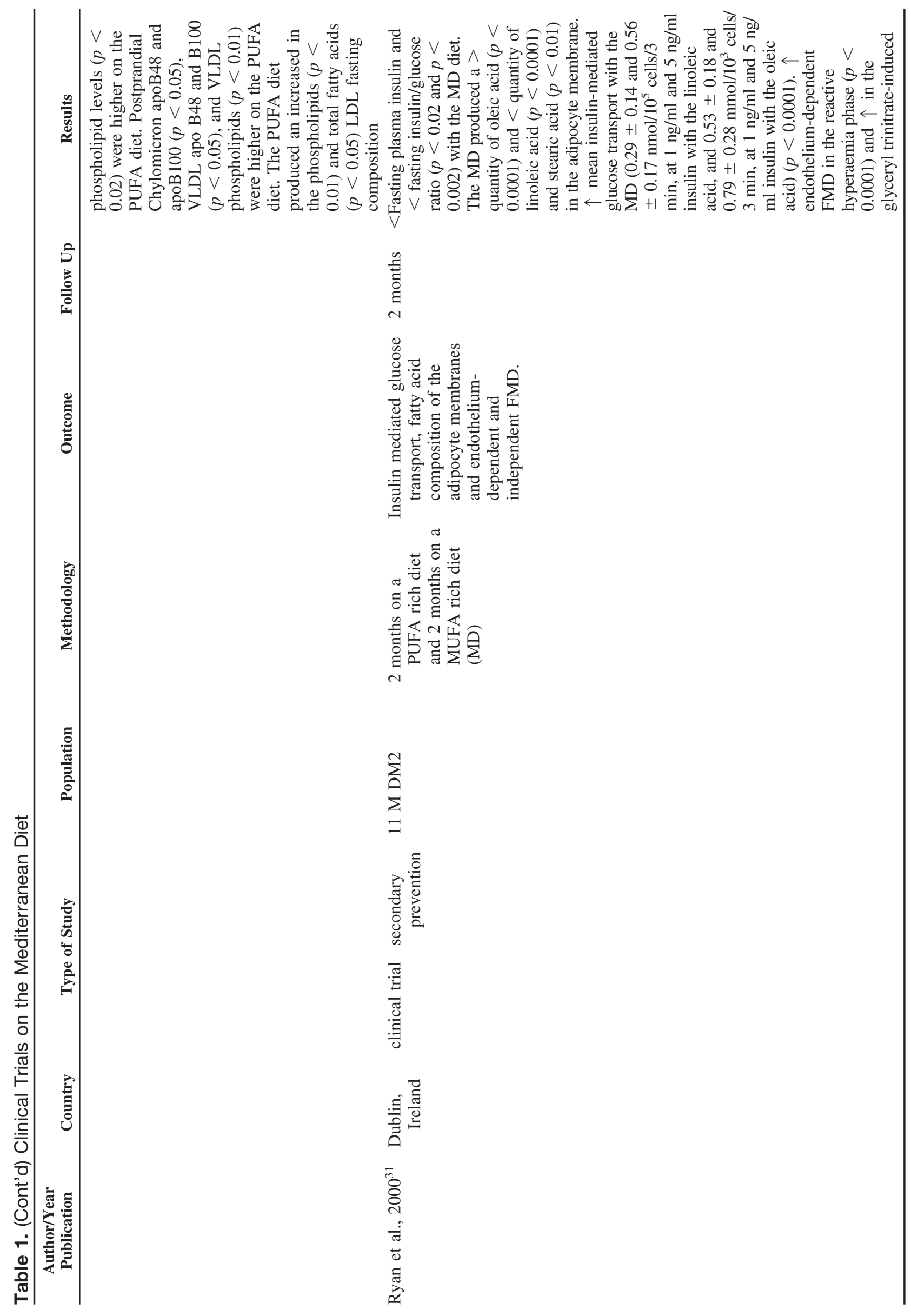




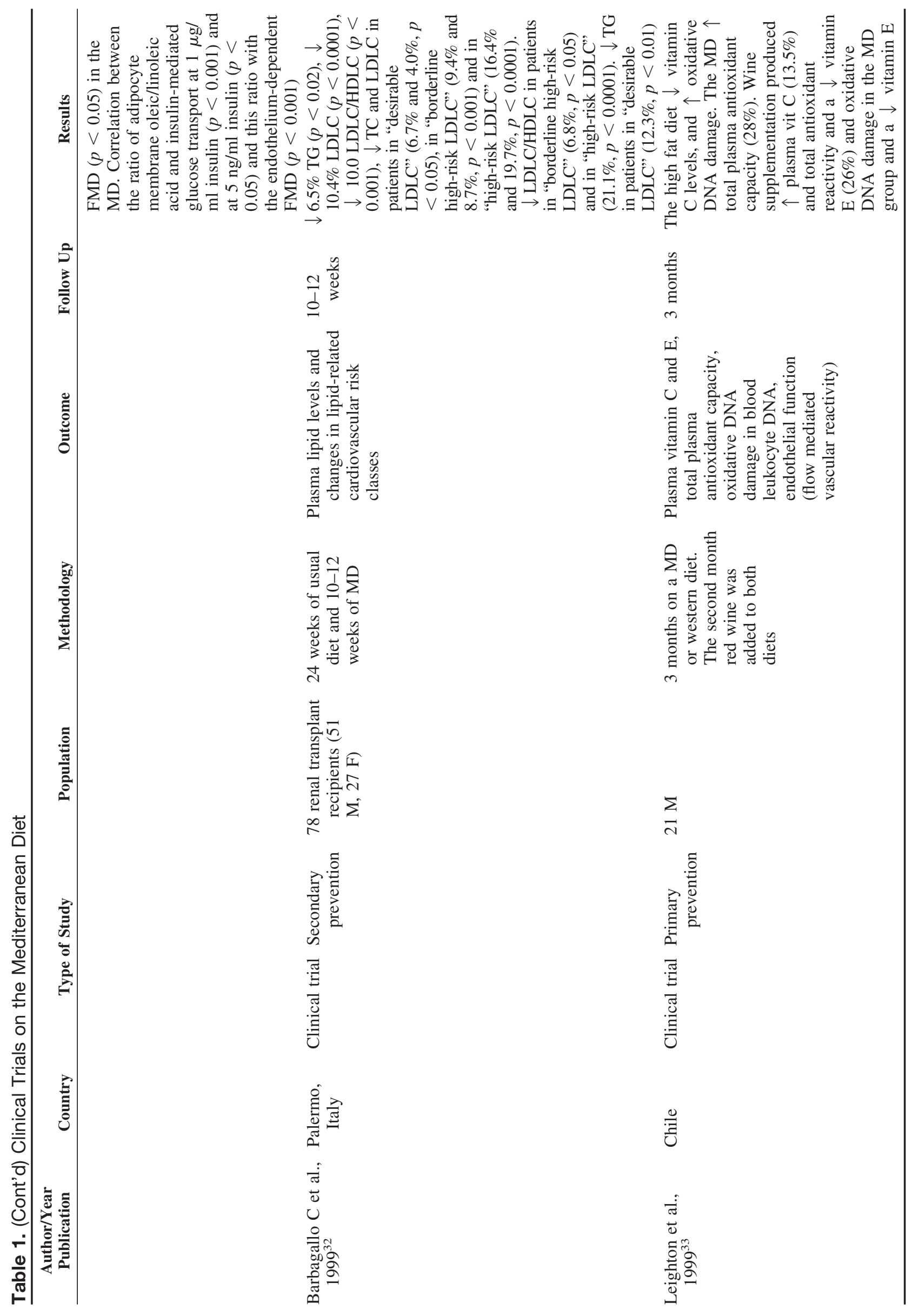




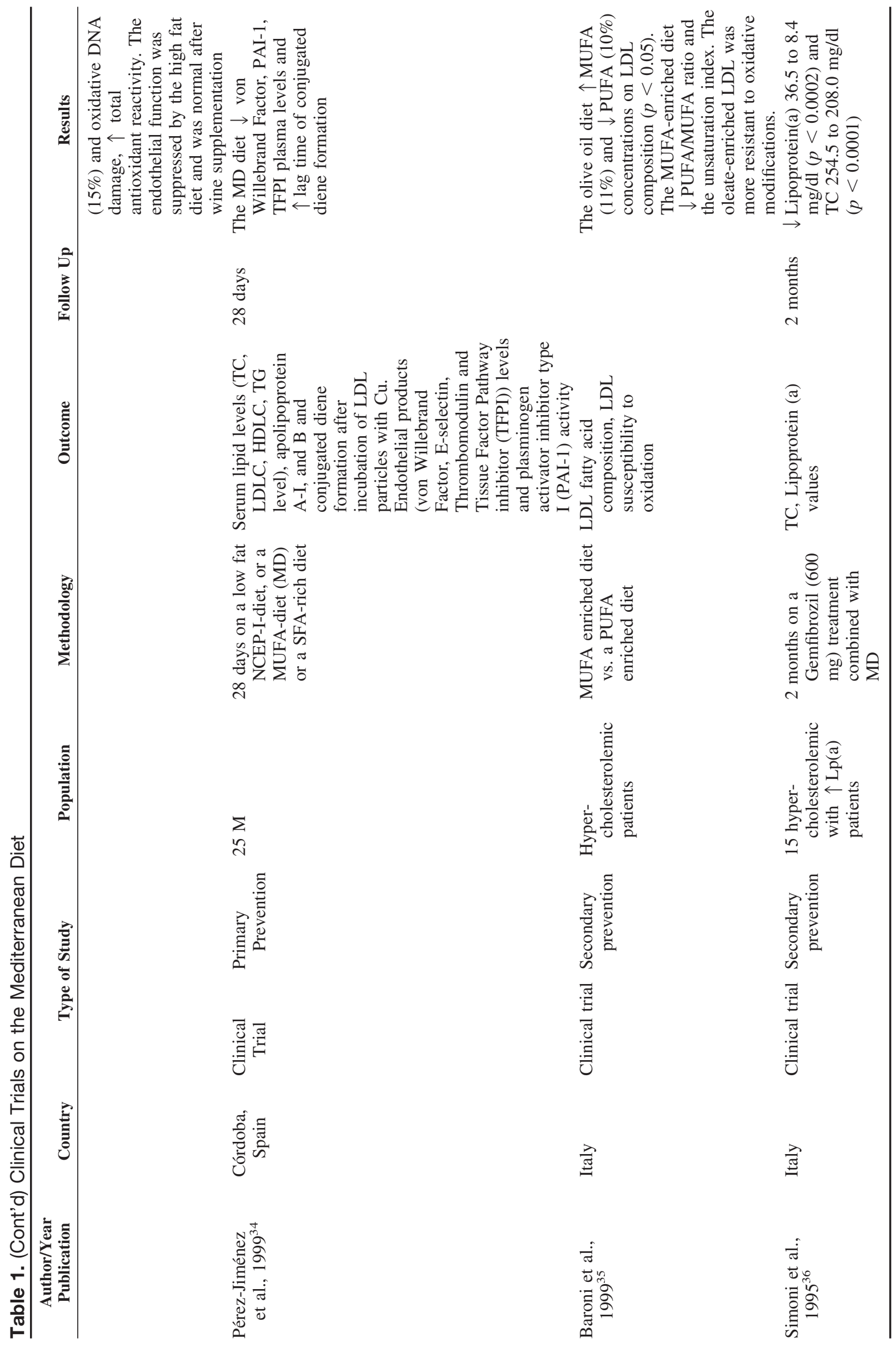




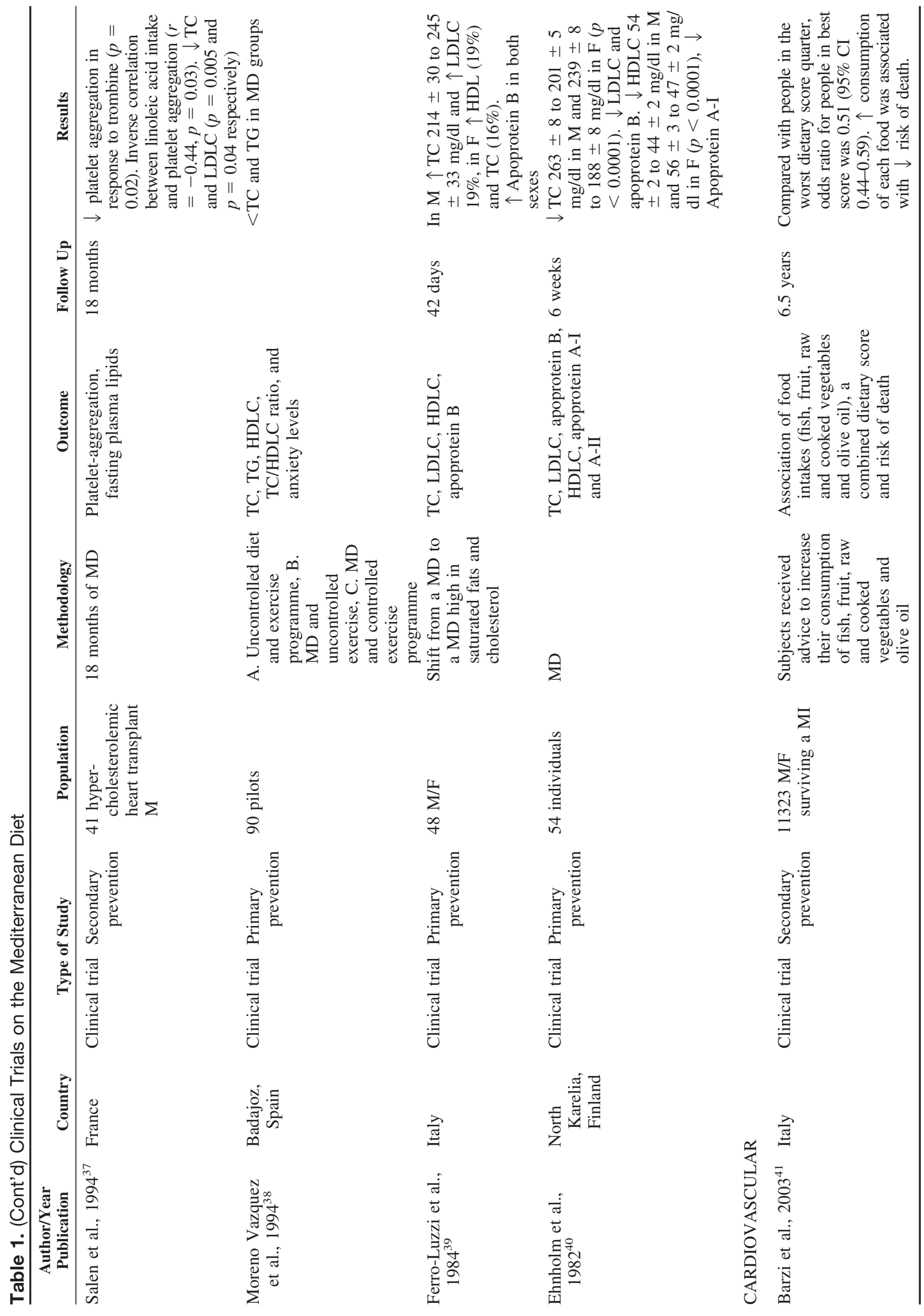




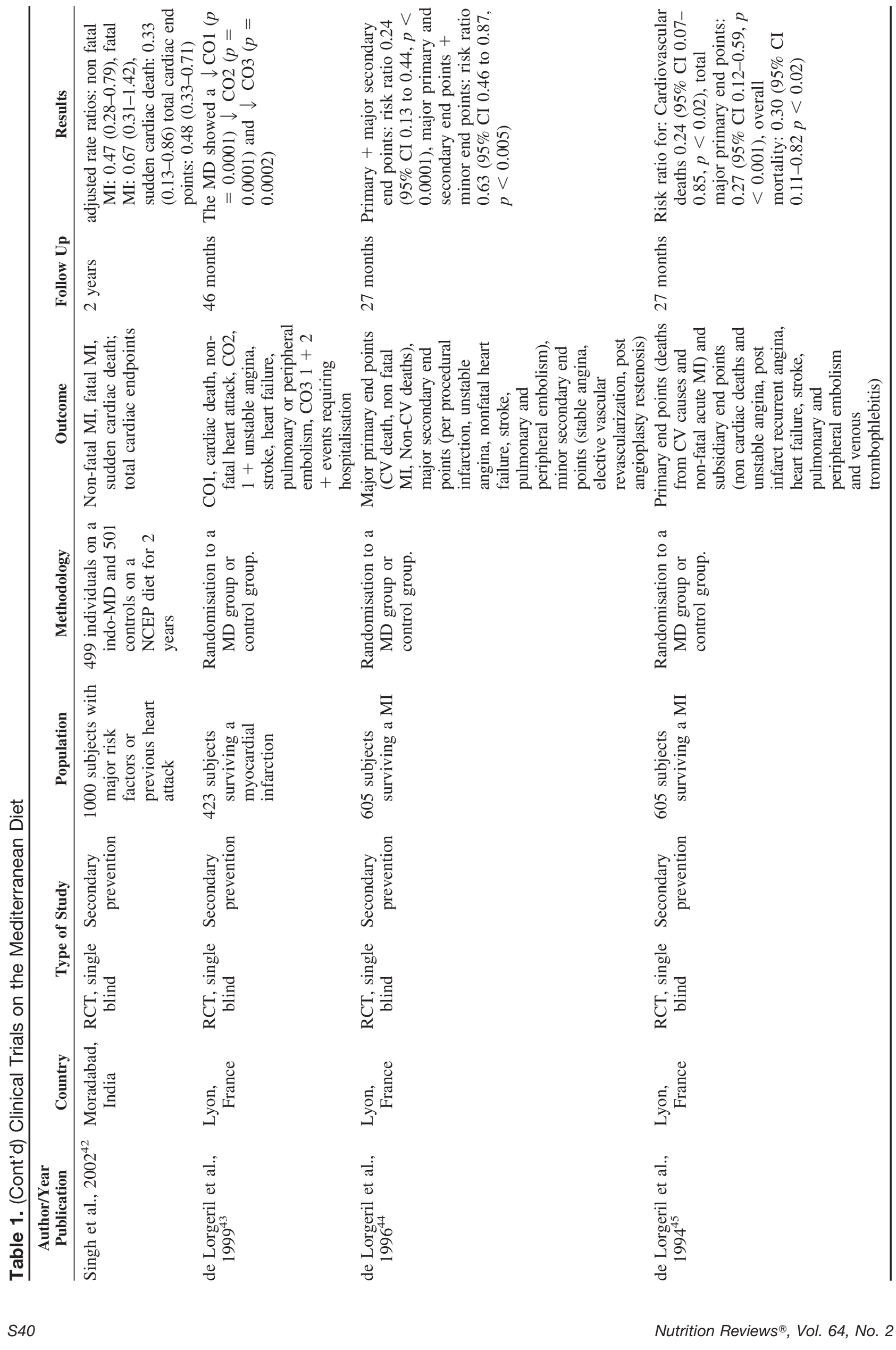




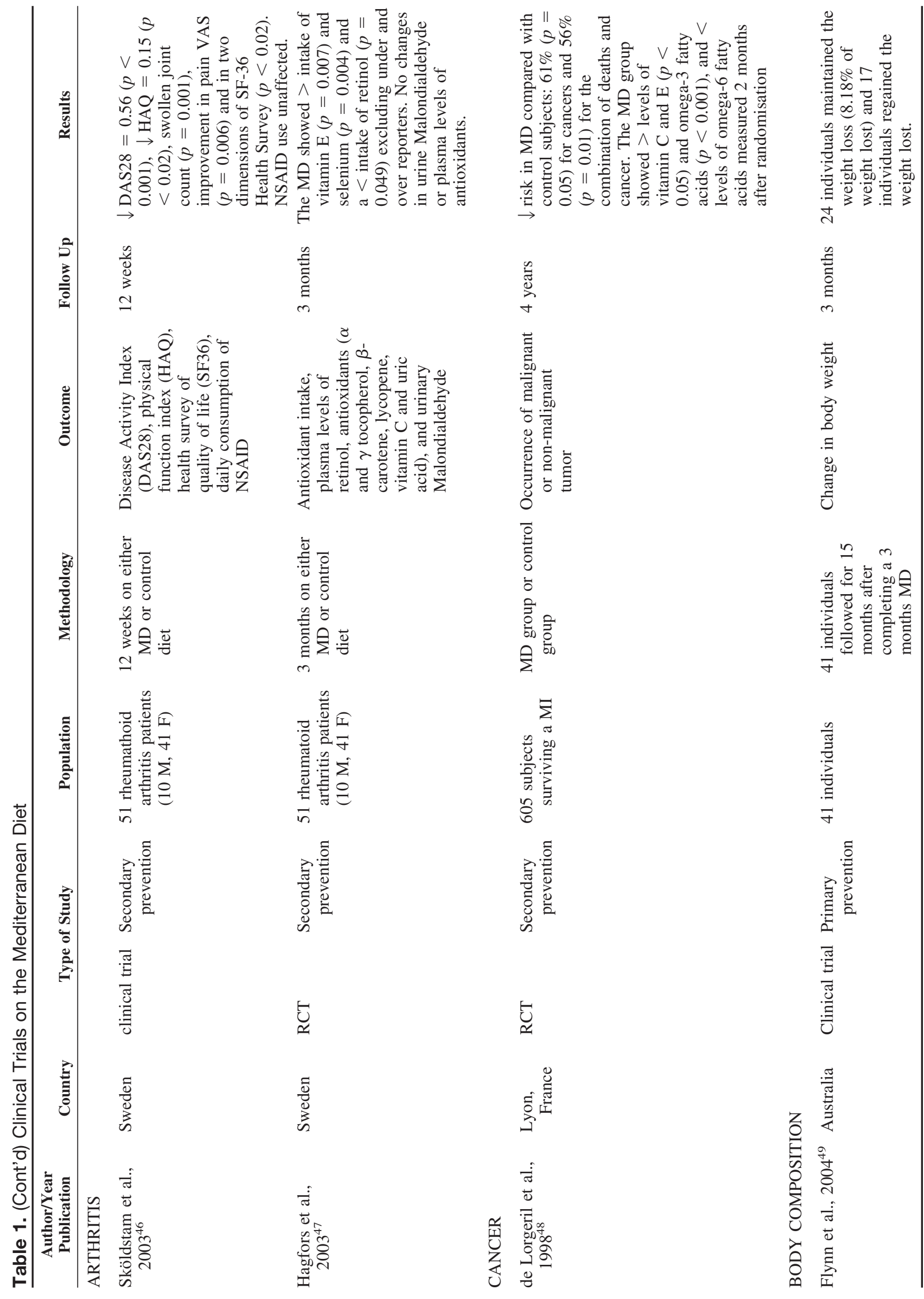




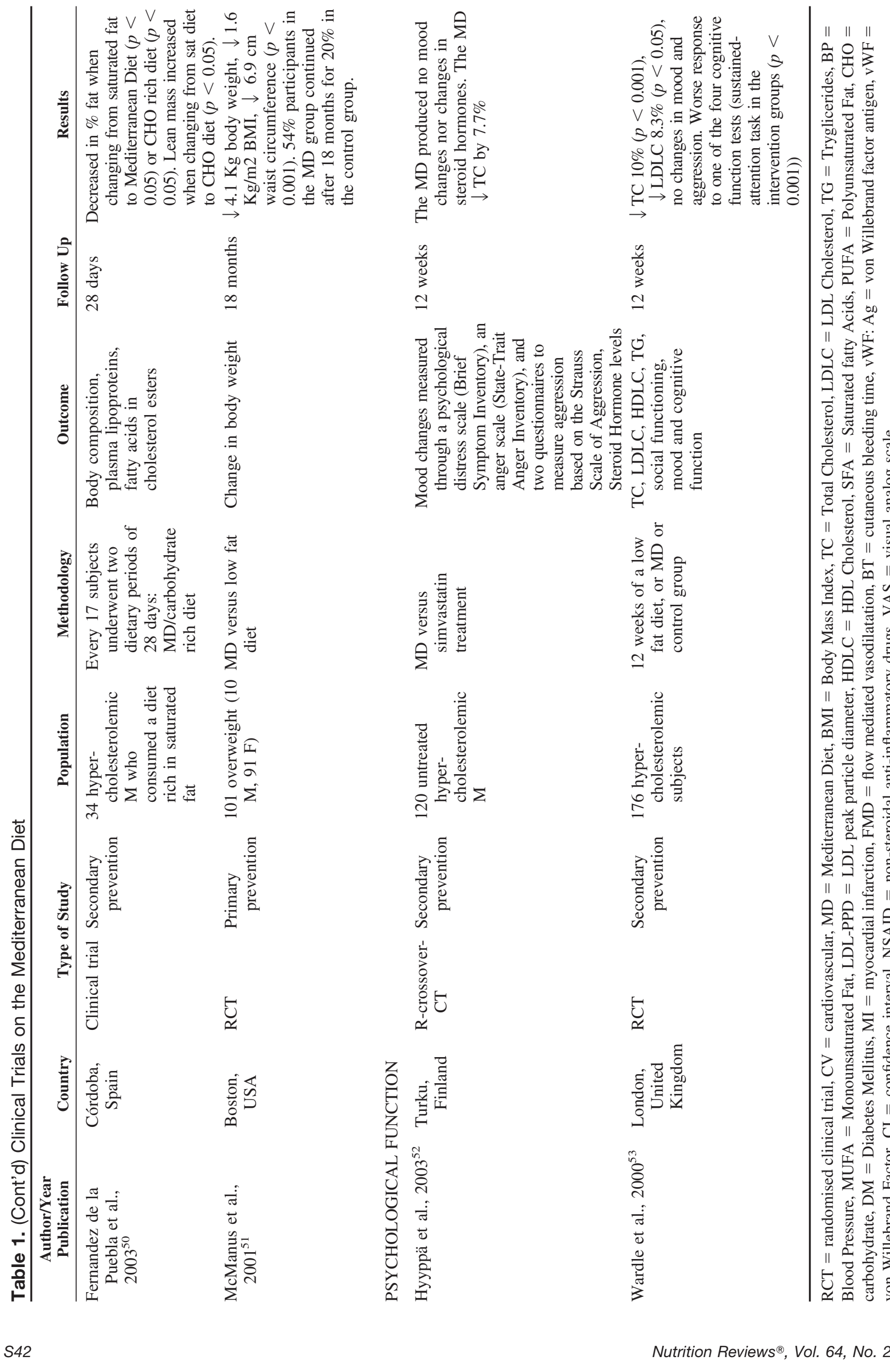


with more than 150 references, and more than $20 \%$ of them from the author himself, yet not one reference from Trichopoulou (author of 27 of the 70 articles related to "diet and Cancer and Greece").

Other examples in the area of obesity and the Mediterranean diet ${ }^{56-58}$ put into evidence the lack of consensus and objectivity that leads to reduced credibility of the research done in Mediterranean countries.

Mediterranean countries have been considered a difficult place to conduct reliable research (experimental studies and large-scale cohort studies), not only due to the traditional subjectivism and lack of cooperation among researchers, but also because of the lack of commitment from the government and other institutions. Additionally, in the past, low priority was given to research careers, particularly in the area of nutrition. ${ }^{59}$ Fortunately, there has been rapid progress in recent years, and the number of original articles addressing the Mediterranean diet have been increasing exponentially since 1999 (Figure 1). The rise of institutions and initiatives dedicated to the Mediterranean diet, such as the Foundation for Advancement of Mediterranean diet, which was founded in 1996, may have contributed to this.

Most of the trials analyzed had a limited number of participants (24 of 43 articles included less than 60 participants in the sample), but the most important limitation is the different methodology used to define the intervention. Some authors characterized the Mediterranean diet just as a monounsaturated fatty acid-rich or -enriched diet; others by additional supplementation with walnuts or wine, but only a few defined a score or pattern of the Mediterranean diet. This is probably one of the major weaknesses of these experimental studies. Changing a group of persons to a particular dietary profile is hard to achieve and particularly difficult to maintain and guarantee compliance.

This review shows that the results of the following studies are of special importance: the Lyon Diet Heart Study, ${ }^{43}$ the Indo Mediterranean Heart Study, ${ }^{42}$ the GISSI Prevention Trial for Secondary Prevention, ${ }^{41}$ the study by Esposito et al. ${ }^{12}$ on metabolic syndrome, and also three ongoing trials on primary prevention: the Mediet Project ${ }^{60}$ in Italy, the Medi-RIVAGE Study ${ }^{11}$ in France, and the PREDIMED study in Spain.

However, most of the small clinical studies analyzed in this review contributed greatly to explaining the mechanisms of how the Mediterranean diet itself or some of its components improve certain biological variables and affect disease outcomes.

Recent findings from two large European cohort studies ${ }^{61,62}$ have suggested that a high degree of adherence to the Mediterranean diet is associated with a reduction in both total and coronary mortality. In addi- tion, modified Mediterranean diets were associated with remarkable reductions in CHD event rates and cardiovascular mortality in two secondary prevention trials carried out in France (Lyon Diet Heart Study) ${ }^{43}$ and India (Indo-Mediterranean diet Heart study). ${ }^{42}$ However, no randomized, controlled trial has been conducted to assess to what extent a Mediterranean diet is superior to the usually recommended low-fat diet in the primary prevention of cardiovascular disease and other chronic diseases. Only two small clinical trials are currently being undertaken: the Mediet Project ${ }^{60}$ in Italy and the Medi-RIVAGE Study ${ }^{11}$ in France. The only large-scale ongoing clinical trial is running in Spain, the PREDIMED Study, which is the most comprehensive and ambitious.

The Mediet Project ${ }^{60}$ is a randomized clinical trial being undertaken to investigate the potential impact of the traditional Mediterranean diet on the risk of developing breast cancer in a sample of 115 women. The study is currently ongoing to verify the association of changes in serum and urine hormone levels and breast cancer risk in the intervention group, who attended a weekly cooking course for one year.

The Medi RIVAGE study ${ }^{11}$ (Mediterranean diet, Cardiovascular Risks and Gene Polymorphisms) is a randomized clinical trial developed in France conducted in a sample of 212 males and females with at least one cardiovascular risk factor. The study has two main goals. The first one is the prevention of cardiovascular diseases by evaluating the effect of two diets (a Mediterraneantype diet and a low-fat, low-cholesterol diet) on arteriosclerosis risk factors. The second goal is to implement extensive biological investigation in relation to the dietary intervention, with a special interest on fasting and postprandial examinations of lipid parameters and lipoproteins, as well as some genetic polymorphisms that influence lipoprotein metabolism and homeostasis. The study is still ongoing. The data at 3 months of follow-up show that in subjects at risk, changing to a Mediterranean-type diet improves blood biochemical parameters.

The PREDIMED Study (PREDIMED meaning PREvención con DIeta MEDiterránea) was initiated in October 2003 with the recruitment of participants for this primary prevention trial. This parallel group, multi-center, randomized study was designed in 2002 and funded by a grant from the official biomedical research agency of the Spanish government, the Spanish Ministry of Health. The PREDIMED Study is the first large-scale, long-term clinical trial that enrolls high-risk patients to follow a Mediterranean diet supplemented with extra virgin olive oil or nuts for primary cardiovascular disease prevention. The US Food and Drug Administration (FDA) has very recently approved a health claim for olive oil as a putative cardio-protective food. ${ }^{63}$ However, 
in this era of evidence-based medicine, definite medical advice and treatment should be supported by the results of randomized clinical trials with clinical events as primary outcomes. The results of the PREDIMED Study could provide the firm evidence required to issue dietary guidelines for sound clinical practice.

The primary outcome to be evaluated in this trial is a composite end point of cardiovascular death, non-fatal myocardial infarction, and non-fatal stroke. As secondary outcomes, death by any cause and incidence of angina leading to a revascularization procedure, heart failure, diabetes mellitus, dementia, and cancer were included. Finally, other outcomes such as changes in blood pressure, body weight, adiposity measures, blood sugar, lipid profile, markers of inflammation, and other intermediate markers of cardiovascular risk will also be measured.

A sample size of 9000 with randomization to three equally sized groups (two intervention groups and one control group, with 3000 patients each) will provide sufficient statistical power to evaluate the effect of the Mediterranean diet on the primary outcome. Participants are free-living high-risk persons age 55 to 80 years for men and 60 to 80 years for women with no history of cardiovascular disease, who fulfill at least one of the two following criteria: 1 ) type 2 diabetes, 2) three or more of these risk factors: current smoker, hypertension, LDL cholesterol $\geq 160 \mathrm{mg} / \mathrm{dL}$, HDL cholesterol $\leq 40 \mathrm{mg} / \mathrm{dL}$, BMI $\geq 25 \mathrm{~kg} / \mathrm{m}^{2}$, or a family history of premature CHD.

The participants included as controls receive recommendations to follow a low-fat diet according to the American Heart Association guidelines. The two intervention group assignments are designated by allotment of either olive oil ( 15 liters $=1$ liter/week for 15 weeks $)$ or packets of walnuts, hazelnuts, and almonds (1350 g walnuts $=15 \mathrm{~g} / \mathrm{d}, 675 \mathrm{~g}$ hazelnuts $=7.5 \mathrm{~g} / \mathrm{d}$, and $675 \mathrm{~g}$ almonds $=7.5 \mathrm{~g} / \mathrm{d}$ for 90 days), together with instructions about their use and conservation. In the intervention groups, personalized advice regarding dietary changes with the aim of achieving an ideal Mediterranean diet is given. A leaflet with written information about the main food components and cooking habits of the Mediterranean diet is provided, together with recommendations on the desired frequency of intake of specific foods. A group session with up to 20 participants, with separate sessions for each of the two Mediterranean diet groups, is scheduled every 3 months and consists of informative talks and the provision of written material with elaborate descriptions of typical Mediterranean foods and shopping lists, meal plans, and recipes adapted to the season of the year. Each session includes three steps: assessment, intervention, and future directions.

Major measurements and data collection activities also take place at baseline and each subsequent year. The baseline visit includes: 1) a general questionnaire; 2) a food-frequency questionnaire with 137 foods plus information on vitamin supplements and alcohol consumption (adapted from the Nurses' Health Study questionnaire and validated in Spain); 3) the Minnesota physical activity questionnaire (validated Spanish version); 4) measurement of weight, height, waist circumference, blood pressure, and ankle-brachial blood pressure index; 5) collection of fasting blood samples and preparation of serum, plasma, and buffy-coat aliquots; 6) collection of urine samples and toenail specimens; and 7) a 47-item general questionnaire with information about risk factors and medication use. The same assessment is performed in the yearly visits, except that the initial questionnaire is substituted by a follow-up questionnaire, which includes new medical diagnoses and medication. Since the information from the food-frequency questionnaire provides only a subjective assessment of compliance, biological markers (plasma fatty acids and urinary tyrosol and hydroxytyrosol) ${ }^{64,65}$ are measured in a random subset $(10 \%)$ of participants from the three arms of the trial to objectively evaluate intervention compliance.

Participants initially recruited will be followed for up to 5 years, and those entering later will be followed for at least 4 years. Consequently, we expect a median follow-up above 4 years. Primary and secondary outcomes will be detected by the primary care physicians of each participant and confirmed by a clinical events subcommittee. It is our hope that the results of the PREDIMED trial will provide strong evidence to establish dietary guidelines to enforce sound clinical practice and public health policy within the Mediterranean Basin.

Mediterranean diet recommendations need to be evidence based, which requires the development of clinical and observational epidemiology in Mediterranean countries. Also, objective systematic (non-personalized) reviews need to address different areas of the relationship between Mediterranean diet and health. ${ }^{66}$ Otherwise, the promotion of the Mediterranean diet will always have shortcomings and thus continue to be viewed with certain misgivings.

\section{ACKNOWLEDGMENTS}

The authors would like to thank Lourdes Ribas and Joy Ngo for their assistance with the preparation and editing of the document.

\section{REFERENCES}

1. Keys A, Menotti A, Karoven MI. The diet and the 15-year death rate in the Seven Countries Study. Am J Epidemiol. 1986;124:903-915.

2. Tunstall-Pedoe $\mathrm{H}$, Kuulasmaa $\mathrm{K}$, Mahonen $\mathrm{M}$, et al. Contribution of trends in survival and coronaryevent rates to changes in coronary heart disease 
mortality: 10 years results from 37 WHO MONICA project populations. Monitoring trends and determinants in cardiovascular disease. Lancet. 1999;353: 1547-1557.

3. Masiá R, Pena J, Marrugat J, et al. High prevalence of cardiovascular risk factors in Gerona, Spain, a province with low myocardial infarction incidence. REGICOR investigators. J Epidemiol Comm Health. 1998;52:707-715.

4. Helsing E, Trichopoulou A. The Mediterranean diet and food culture: a symposium. Eur J Clin Nutr. 1989;43(suppl 1):1-92.

5. Serra Majem L, Helsing E. Changing patterns of fat intake in Mediterranean countries. Eur J Clin Nutr. 1993;47(suppl 1):1-100.

6. Nestle E. Mediterranean diets: science and policy implications. Am J Clin Nutr. 1995;61(suppl 6):13131427.

7. Willett WC, Sacks F, Trichopoulou A, et al. Mediterranean diet pyramid: a cultural model for healthy eating. Am J Clin Nutr. 1995;61(suppl 6):1402-1406.

8. Trichopoulou A, Lagiou P. Healthy traditional Mediterranean diet: an expression of culture, history, and lifestyle. Nutr Rev. 1997;55:383-389.

9. Serra Majem L, Ngo de la Cruz J (eds). ¿Qué es la dieta Mediterránea?. Barcelona: Nexus Ediciones. 2002:1-221.

10. Serra Majem L, Trichopoulou A, Ngo de la Cruz J, et al. Foreword: does the definition of the Mediterranean diet need to be updated? Public Health Nutr. 2004;7:927-929.

11. Vincent S, Gerber M, Bernard MC, et al. The MediRIVAGE study (Mediterranean diet, cardiovascular risks and gene polymorphisms): rationale, recruitment, design, dietary intervention and baseline characteristics of participants. Public Health Nutr. 2004;7:531-542.

12. Esposito K, Marfella R, Ciotola M, et al. Effect of a Mediterranean-style diet on endothelial dysfunction and markers of vascular inflammation in the metabolic syndrome: a randomized trial. JAMA. 2004; 292:1440-1446.

13. Ros E, Nunez I, Perez-Heras A, et al. A walnut diet improves endothelial function in hypercholesterolemic subjects: a randomized crossover trial. Circulation. 2004;109:1609-1614.

14. Ambring A, Friberg $P$, Axelsen M, et al. Effects of a Mediterranean-inspired diet on blood lipids, vascular function and oxidative stress in healthy subjects. Clin Sci. 2004;106:519-525.

15. Goulet J, Lamarche B, Charest A, et al. Effect of a nutritional intervention promoting the Mediterranean food pattern on electrophoretic characteristics of low-density lipoprotein particles in healthy women from the Quebec City metropolitan area. Br J Nutr. 2004;92:285-293.

16. Flynn G, Colquhoun D. Mediterranean diet improves lipid profiles over three months. Asia Pac J Clin Nutr. 2004;13(suppl):S138.

17. Urquiaga I, Guasch V, Marshall G, et al. Effect of Mediterranean and occidental diets, and red wine, on plasma fatty acids in humans. An intervention study. Biol Res. 2004;37:253-261.

18. Bravo-Herrera MD, Lopez-Miranda J, Marin C, et al. Tissue factor expression is decreased in monocytes obtained from blood during Mediterranean or high carbohydrate diets. Nutr Metab Cardiovasc Dis. 2004;14:128-132.

19. Toobert DJ, Glasgow RE, Strycker LA, et al. Biologic and quality-of-life outcomes from the Mediterranean Lifestyle Program: a randomized clinical trial. Diabetes Care. 2003;26:2288-2293.

20. Rodríguez-Villar C, Pérez-Heras A, Mercadé I, et al. Comparison of a high-carbohydrate and a high monounsaturated fat, olive oil-rich diet on the susceptibility of LDL to oxidative modification in subjects with type 2 diabetes mellitus. Diabet Med. 2004;21:142-149.

21. Goulet J, Lamarche B, Nadeau G, Lemieux S. Effect of a nutritional intervention promoting the Mediterranean food pattern on plasma lipids, lipoproteins and body weight in healthy French-Canadian women. Atherosclerosis. 2003;170:115-124.

22. Sondergaard E, Moller JE, Egstrup K. Effect of dietary intervention and lipid-lowering treatment on brachial vasoreactivity in patients with ischemic heart disease and hypercholesterolemia. Am Heart J. 2003;145:19.

23. Mezzano D, Leighton F, Strobel P, et al. Mediterranean diet, but not red wine, is associated with beneficial changes in primary haemostasis. Eur J Clin Nutr. 2003;57:439-446.

24. Singh N, Graves J, Taylor PD, et al. Effects of a 'healthy' diet and of acute and long-term vitamin $\mathrm{C}$ on vascular function in healthy older subjects. Cardiovasc Res. 2002;56:118-125.

25. Perez-Jimenez F, Lopez-Miranda J, Pinillos MD, et al. A Mediterranean and a high-carbohydrate diet improve glucose metabolism in healthy young persons. Diabetologia. 2001;44:2038-2043.

26. Mezzano D, Leighton F, Martinez C, et al. Complementary effects of Mediterranean diet and moderate red wine intake on haemostatic cardiovascular risk factors. Eur J Clin Nutr. 2001;55:444-451.

27. Fuentes F, Lopez-Miranda J, Sanchez E, et al. Mediterranean and low-fat diets improve endothelial function in hypercholesterolemic men. Ann Intern Med. 2001;134:1115-1159.

28. Muñoz S, Merlos M, Zambon D, et al. Walnutenriched diet increases the association of LDL from hypercholesterolemic men with human HepG2 cells. J Lipid Res. 2001;42:2069-2076.

29. Zambon D, Sabate J, Munoz S, et al. Substituting walnuts for monounsaturated fat improves the serum lipid profile of hypercholesterolemic men and women. A randomized crossover trial. Ann Intern Med. 2000;132:538-546.

30. Madigan C, Ryan M, Owens D, et al. Dietary unsaturated fatty acids in type 2 diabetes: higher levels of postprandial lipoprotein on a linoleic acid-rich sunflower oil diet compared with an oleic acid-rich olive oil diet. Diabetes Care. 2000;23:1472-1477.

31. Ryan M, Mclnerney D, Owens D, et al. Diabetes and the Mediterranean diet: a beneficial effect of oleic acid on insulin sensitivity, adipocyte glucose transport and endothelium-dependent vasoreactivity. QJM. 2000;93:85-91.

32. Barbagallo CM, Cefalu AB, Gallo S, et al. Effects of Mediterranean diet on lipid levels and cardiovascu- 
lar risk in renal transplant recipients. Nephron. 1999; 82:199-204.

33. Leighton F, Cuevas A, Guasch V, et al. A. Plasma polyphenols and antioxidants, oxidative DNA damage and endothelial function in a diet and wine intervention study in humans. Drugs Exp Clin Res. 1999;25:133-141.

34. Perez-Jimenez F, Castro P, Lopez-Miranda J, et al. Circulating levels of endothelial function are modulated by dietary monounsaturated fat. Atherosclerosis. 1999;145:351-358.

35. Baroni SS, Amelio M, Sangiorgi Z, et al. Solid monounsaturated diet lowers LDL unsaturation trait and oxidisability in hypercholesterolemic (type Ilb) patients. Free Radic Res. 1999;30:275-285.

36. Simoni G, Gianotti A, Ardia A, et al. Gemfibrozil and Mediterranean diet for patients with high plasma levels of lipoprotein [Lp(a)] and cholesterol-pilot study. Cardiovasc Drugs Ther. 1995;9:347-350.

37. Salen $P$, de Lorgeril $M$, Boissonnat $P$, et al. Effects of a French Mediterranean diet on heart transplant recipients with hypercholesterolemia. Am J Cardiol. 1994;73:825-827.

38. Moreno Vazquez JM, Garcia Alcon JL, Campillo Alvarez JE. Influence of diet and physical exercise on plasma lipid concentrations in an homogeneous sample of young Spanish air force pilots. Eur J Appl Physiol Occup Physiol. 1994;69:75-80.

39. Ferro-Luzzi A, Strazzullo P, Scaccini C, et al. Changing the Mediterranean diet: effects on blood lipids. Am J Clin Nutr. 1984;40:1027-1037.

40. Ehnholm C, Huttunen JK, Pietinen P, et al. Effect of diet on serum lipoproteins in a population with a high risk of coronary heart disease. $\mathrm{N}$ Engl J Med. 1982;307:850-855.

41. Barzi F, Woodward M, Marfisi RM, et al. Mediterranean diet and all-causes mortality after myocardial infarction: results from the GISSI-Prevenzione trial. Eur J Clin Nutr. 2003;57:604-611.

42. Singh RB, Dubnov G, Niaz MA, et al. Effect of an Indo-Mediterranean diet on progression of coronary artery disease in high risk patients (Indo-Mediterranean diet Heart Study): a randomized single-blind trial. Lancet. 2002 ;360:1455-1461.

43. de Lorgeril M, Salen P, Martin JL, et al. Mediterranean diet, traditional risk factors, and the rate of cardiovascular complications after myocardial infarction: final report of the Lyon Diet Heart Study. Circulation. 1999;99:779-785.

44. de Lorgeril M, Salen P, Martin JL, et al. Effect of a Mediterranean type of diet on the rate of cardiovascular complications in patients with coronary artery disease. Insights into the cardioprotective effect of certain nutriments. J Am Coll Cardiol. 1996; 28:1103-1108.

45. de Lorgeril M, Renaud S, Mamelle N, et al. Mediterranean alpha-linolenic acid-rich diet in secondary prevention of coronary heart disease. Lancet. 1994; 343:1454-1459.

46. Skoldstam L, Hagfors L, Johansson G. An experimental study of a Mediterranean diet intervention for patients with rheumatoid arthritis. Ann Rheum Dis. 2003;62:208-214.

47. Hagfors L, Leanderson P, Skoldstam L, et al. Antioxidant intake, plasma antioxidants and oxidative stress in a randomized, controlled, parallel, Mediterranean dietary intervention study on patients with rheumatoid arthritis. Nutr J. 2003;2:5.

48. de Lorgeril M, Salen P, Martin JL, et al. Mediterranean dietary pattern in a randomized trial: prolonged survival and possible reduced cancer rate. Arch Intern Med. 1998;158:1181-1187.

49. Flynn G, Colquhoun D. Successful long-term weight loss with a Mediterranean style diet in a primary care medical center. Asia Pac J Clin Nutr. 2004; 13(suppl):S139.

50. Fernandez de la Puebla RA, Fuentes F, Perez-Martinez $P$, et al. A reduction in dietary saturated fat decreases body fat content in overweight, hypercholesterolemic males. Nutr Metab Cardiovasc Dis. 2003;13:273-277.

51. McManus K, Antinoro L, Sacks F. A randomized controlled trial of a moderate-fat, low-energy diet compared with a low fat, low-energy diet for weight loss in overweight adults. Int $\mathrm{J}$ Obes Relat Metab Disord. 2001;25:1503-1511.

52. Hyyppa MT, Kronholm E, Virtanen A, et al. Does simvastatin affect mood and steroid hormone levels in hypercholesterolemic men? A randomized double-blind trial. Psychoneuroendocrinology. 2003;28: 181-194.

53. Wardle J, Rogers $P$, Judd $P$, et al. Randomized trial of the effects of cholesterol-lowering dietary treatment on psychological function. Am J Med. 2000; 108:547-553.

54. Simopoulos AP. The Mediterranean diets: what is so special about the diet of Greece? The scientific evidence. J Nutr. 2002;13:3065S-3073S.

55. Simopoulos AP. The traditional diet of Greece and cancer. Eur J Cancer Prev. 2004;13:219-230.

56. Ferro-Luzzi A, James WP, Kafatos A. The high-fat Greek diet: a recipe for all?. Eur J Clin Nutr. 2002; 56:796-809.

57. Trichopoulos D. In defense of the Mediterranean diet: a letter to the editor. Eur J Clin Nutr. 2002;56: 928-929.

58. Ferro-Luzzi A, James WPT, Kafatos A. Response to the letter submitted by D Trichopoulos entitled 'In defense of the Mediterranean diet'. Eur J Clin Nutr. 2002;56:928-929.

59. Serra-Majem L, Ferro-Luzzi A, Bellizzi MC, Salleras L. Nutrition policies in Mediterranean Europe. Nutr Rev. 1997;55(suppl 2):S42-S57.

60. Castagnetta L, Granata OM, Cusimano R, et al. The Mediet project. Ann N Y Acad Sci. 2002;963:282289.

61. Knoops KTB, de Groot LCPGM, Kromhout D, et al. Mediterranean diet, lifestyle factors and 10-year mortality in elderly European men and women. JAMA. 2004;292:1433-1439.

62. Trichopoulou A, Costacou T, Barnia C, Trichopoulos D. Adherence to Mediterranean diet and survival in a Greek population. N Engl J Med. 2003;348: 2599-2508.

63. Food and Drug Administration. FDA Allows Qualified Health Claim to Decrease Risk of Coronary Heart Disease. Available online at: http://www. fda.gov/bbs/topics/news/2004/NEW01129.html. Accessed January 9, 2006.

64. Miró-Casas E, Farre Alvadalejo M, Covas M-I, et al. 
Cappillary gas chromatography-mass spectrometry quantitative determination of hydrosytyrosol and tyrosol in human urine after olive oil intake. Analytical Biochem. 2001;294:63-72.

65. Bondia-Pons I, Castellote Al, and Lopez-Sabaté C. Comparison of conventional and fast gas chroma- tography in human plasma fatty acid determination. J Chromatography. 2004;809:339-344.

66. Martínez-González MA, Estruch R. Mediterranean diet, antioxidants and cancer: the need for randomized trials. Eur J Cancer Prev. 2004;13:327335. 